\title{
International Journal of
}

\section{Modern Education and Computer Science}

\section{Kol.9}

No. 10 Oct. 2017

\section{IJMECS Kol.9}

Http:// www.mecs-press .org Vol. 9 No. 10 October 2017 


\section{International Journal of Modern Education and Computer Science (IJMECS)}

ISSN Print: 2075-0161, ISSN Online: 2075-017X

Volume 9, Number 10, October 2017

\section{Contents}

\section{REGULAR PAPERS}

About Big Data Measurement Methodologies and Indicators

Makrufa Sh. Hajirahimova, Aybeniz S. Aliyeva

Evaluation Framework for Disabled Students based on Speech Recognition Technology

Sanjay Kumar Pal, Seemanta Bhowmick

Use of Intelligent Agents in Collaborative M-Learning: Case of Facilitating Group Learner Interactions

Stephen T. Njenga, Robert O. Oboko, Elijah I. Omwenga, Elizaphan M. Maina

Analyzing the Performance of SVM for Polarity Detection with Different Datasets

Munir Ahmad, Shabib Aftab

Recommendation Techniques in Mobile Learning Context: A Review

Nassim DENNOUNI, Zohra SLAMA, Yvan PETER, Luigi LANCIERI

An Identity-based Blind Signature Approach for E-voting System

Mahender Kumar, C.P. Katti, P. C. Saxena

The Role of Learner Characteristics in the Adaptive Educational Hypermedia Systems: The Case of the

Alexandros Papadimitriou, Georgios Gyftodimos 